\title{
Use of quick and hydrated lime in stabilization of lateritic soil: comparative analysis of laboratory data
}

\author{
A. A. Amadi and A. Okeiyi
}

\begin{tabular}{l}
\hline${ }^{*}$ Correspondence: \\
agapitus.amadi@ \\
futminna.edu.ng; \\
agapitusahamefule4@yahoo. \\
com \\
Department of Civil \\
Engineering, Federal \\
University of Technology, \\
Minna, Nigeria
\end{tabular}

*Correspondence: agapitus.amadi@ agapitusahamefule4@yahoo. com Minna, Nigeria

\begin{abstract}
A laboratory study was undertaken to evaluate and compare the stabilization effectiveness of different percentages $(0,2.5,5,7.5,10 \%)$ of quick and hydrated lime when applied separately to locally available lateritic soil, a major soil group in the tropical and sub tropical regions. Performance evaluation experiments included: Atterberg limits, compaction, unconfined compression tests, California bearing ratio (CBR), swelling potential using CBR instrument and hydraulic conductivity. The soil mixtures used for unconfined compressive strength (UCS), CBR, swelling potential and hydraulic conductivity tests were compacted at optimum moisture content using the British standard light compactive effort and cured for 28 days. It was found that the quicklime caused the soil to have lower plasticity while hydrated lime yielded higher dry unit weight. Also, higher UCS especially at higher dosages (7.5 and 10\%) was produced when soil sample was treated with quicklime. Similarly, the CBR values for quicklime sample clearly indicate that quicklime-stabilized soil have superior load bearing capacity. Finally, quicklime treated specimens reached slightly lower swelling values than the hydrated lime while no appreciable distinction in hydraulic conductivity values of specimens treated with the two types of lime was observed. From the foregoing results, quicklime is adjudged to have exhibited somewhat superior engineering properties and therefore creates a more effective stabilization alternative for the soil.
\end{abstract}

Keywords: Hydrated lime, Quicklime, Lateritic soil, Effective stabilization

\section{Background}

It is common practice to use chemical additives to stabilize soft and/or wet fine grained soils before they are built upon or used for embankment. Through the stabilization process, the plasticity of soil is reduced, it becomes more workable, and its compressive strength and load bearing properties are improved. Such improvements are the result of a number of chemical processes that take place in the presence of the stabilizer. The stabilizer alters the physicochemical properties of soil which also ensure the preservation of macro structural integrity with minimal degradation under the combined effect of extreme climatic conditions and loading over the designed service period [7, 13, 18, 19]. The process is not only cost effective, but it also lessens the demand on non-renewable resources and reduces the environmental footprint of civil engineering projects.

(c) The Author(s) 2017. This article is distributed under the terms of the Creative Commons Attribution 4.0 International License (http://creativecommons.org/licenses/by/4.0/), which permits unrestricted use, distribution, and reproduction in any medium, provided you give appropriate credit to the original author(s) and the source, provide a link to the Creative Commons license, and indicate if changes were made. 
Lime stabilization technology is an attractive stabilization technique most widely used in geotechnical and geoenvironmental applications when the project requires improvement of the local soil $[3,10,17,26]$. Many types and qualities of lime have been successfully used as soil stabilizing agents for many years. However, the most widely used and best performing limes in soil stabilization are the quicklime $(\mathrm{CaO})$ and hydrated $\left(\mathrm{Ca}(\mathrm{OH})_{2}\right)$ lime. While both quick and hydrated limes are capable of providing calcium ions $\left(\mathrm{Ca}^{2+}\right)$ in sufficient amount, the primary ingredient necessary for stabilizing a clay soil, they differ slightly in the mode of reaction in the presence of water $[7,13,24,27]$. Based on this difference, it is therefore important to evaluate ultimate superiority of one over the other in lateritic soil stabilization. This ensures the most appropriate lime source will be chosen during lime stabilization of this soil group.

A wide range of investigations have been conducted on lime stabilization of soils in the past $[2,3,9,10,16,17,22,27]$. The most notable effect of lime on fine-grained soils is to produce decreased plasticity, increased workability, reduced swelling and shrinkage potential as well as increased strength $[1,6,14,16]$.

Of these two types of lime, research has shown that more strength development occurs in soil-quicklime mixtures rather than hydrated lime [3, 6]. Also, very rapid stabilisation of water-logged sites or very wet materials has been achieved with the use of quicklime [3]. Hydrated lime on the other hand is used extensively for the stabilisation of soils with high clay content where its main advantage is in raising the plastic limit of the clayey soil $[2,8]$. Beyond these, it has also been reported that the relative stabilizing effect correlates well with the calcium oxide $(\mathrm{CaO})$ content of various limes $[6,10,17,27]$.

The primary chemical reactions that occur when lime is mixed with soil and water are cation exchange, flocculation and agglomeration as well as pozzolanic reactions. As lime dissolves in water, the calcium $\left(\mathrm{Ca}^{2+}\right)$ and hydroxyls $\left(\mathrm{OH}^{-}\right)$disassociate making the divalent calcium ions available for exchange with cations in the diffuse double layer of clay particles. The cation exchange and increased ionic concentration of the pore water results in a contraction of the diffuse double layer, flocculation and agglomeration of particles, and nearly instantaneous reduction in plasticity index (PI) with improved workability $[6,14,24]$.

Another consequence of dissolution of lime is an increase in $\mathrm{pH}$ of the soil-water-lime mixture due to the increased concentration of hydroxyl ions. The increased $\mathrm{pH}$ causes silica and alumina associated with clay particles to become soluble. Thus, the lime provides the calcium and a proper chemical environment, while the soil provides the silica and alumina ions necessary to form cementitious compounds i.e. calcium-alumina silicates. These clay silicates and clay aluminates bond or gel to the clay particles together to further strengthen the soil. This reaction is dependent on time in the fact that the longer a specimen is allowed to cure, the more the clay reacts with the lime and the higher the strength $[1,14]$.

The objective of this study was to evaluate and compare the stabilization effectiveness of different percentages $(0,2.5,5,7.5$ and $10 \%)$ of quick and hydrated lime when applied separately to lateritic soil. Performance evaluation experiments included: Atterberg limits, compaction, unconfined compression tests (UCT), California bearing ratio (CBR), swelling potential using CBR instrument and hydraulic conductivity. 


\section{Methods}

The lateritic soil used in this study was obtained locally from a lateritic soil formation in Minna (latitude $9^{\circ} 37^{\prime} \mathrm{N}$ and longitude $6^{\circ} 33^{\prime} \mathrm{E}$ ), Nigeria. All samples were collected in their disturbed state and from a sufficient depth below the ground surface (i.e. 2.0-2.5 m). It is a natural reddish brown soil (Fig. 1) with inclusions of white mottles and belongs to the group of ferruginous tropical soils derived from acidic igneous and metamorphic rocks [22].

The quick and hydrated limes used in the study are the industrial grade available (Fig. 2a, b). To preserve them from carbonation, each bag of lime was double bagged with black plastic bags that were securely tied.

Prior to lime treatment (quick and hydrated limes), the soil sample was air dried and pulverized in a crusher to less than $4.75 \mathrm{~mm}$ size for testing (samples for Atterberg limit tests were pulverized to pass through BS No. $200(425 \mu \mathrm{m})$. In order to stabilize the soil, appropriate amount $(0,2.5,5,7.5$ and $10 \%$ by dry weight of soil) of quicklime and hydrated lime was separately added to the soil.

Atterberg limits of specimens were determined in general accordance with BS 1377 and BS 1924 [4, 5] (standard test methods for liquid limit, plastic limit, and plasticity index of soils).

Compaction tests were conducted to determine the optimum moisture content $(\mathrm{OMC})$ and maximum dry unit weight $\left(\gamma_{\mathrm{dmax}}\right)$ of untreated soil as well as soil sample treated separately with quick and hydrated limes using British standard light (BSL) compaction effort as per BS 1377 and 1924 [4, 5]. Treated soil specimens were delayed for $24 \mathrm{~h}$ after mixing before compaction.

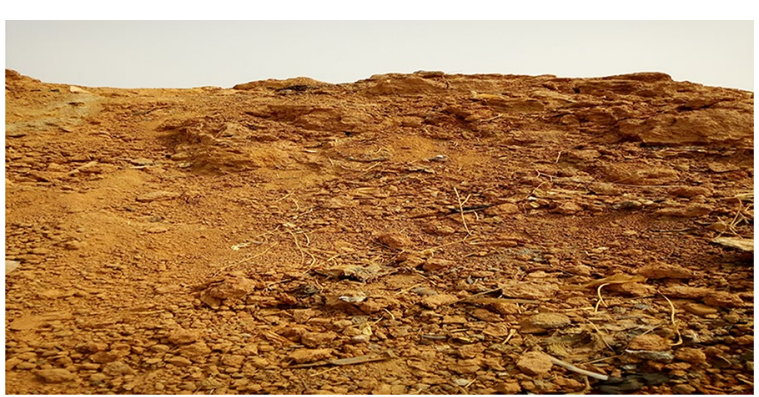

Fig. 1 A lateritic soil quarry in Minna, Nigeria

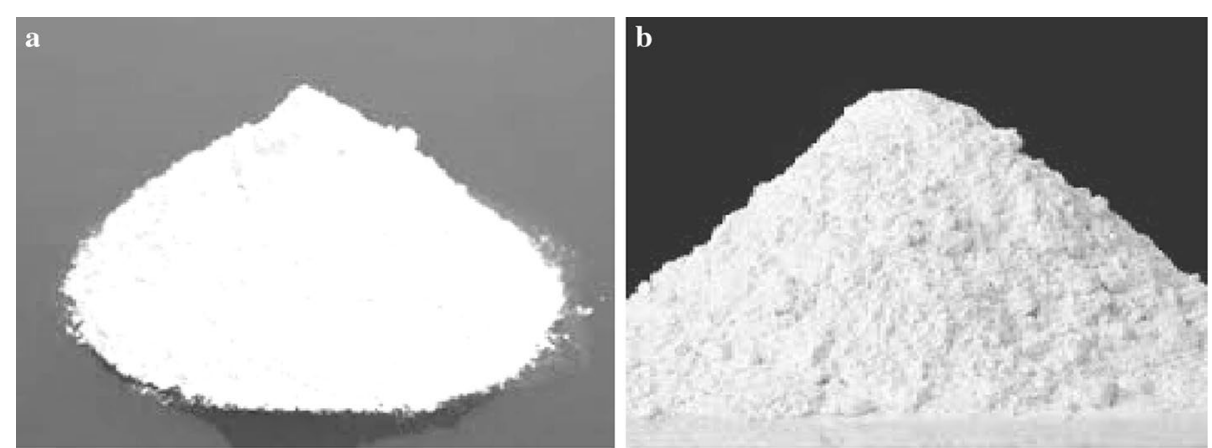

Fig. 2 Photograph of limes used in this study a quicklime, b hydrated lime 
Specimens for unconfined compression (UC) testing were prepared with appropriate dosages of quick and hydrated limes at optimum water content. Upon demoulding, the compacted specimens were placed in resealable plastic bags and stored in a humidity room $(100 \% \mathrm{RH})$ at temperature of $22 \pm 2{ }^{\circ} \mathrm{C}$ to cure for 28 days before conducting the tests. The moist room curing minimizes any loss of moisture from sample, while the plastic bags prevent transfer of moisture from outside.

Unconfined compression tests were conducted on a strain-controlled triaxial testing frame (Fig. 3) at a strain rate of 2\% per minute following procedures outlined in BS 1377 and $1924[4,5]$.

CBR tests were conducted on compacted natural lateritic soil and specimens containing different amounts of quick and hydrated limes prepared at the optimum moisture content. Specimens stabilized with the two types of lime were cured for 28 days in the same conditions as in specimens for UC test. At the end of curing period, the unsoaked CBR of the untreated soil and those treated with quick and hydrated limes was measured. To obtain the soaked CBR values, perforated base plate was attached to the bottom of the CBR mould to allow for the ingress of water during soaking. Specimens were placed in a CBR soaking tank for $96 \mathrm{~h}$. At the end of $96 \mathrm{~h}$ soaking period, CBR of soaked specimens, (untreated soil and those stabilized with quick and hydrated limes) was measured by a CBR equipment (Fig. 4) following BS 1377 and $1924[4,5]$.

Specimens for CBR swell test were however, soaked for an extended period of 28 days before measurements were taken to ensure that all swelling has ceased. At the end of this period, calipers were used to measure the change in specimen height.

Hydraulic conductivity of specimens was measured for untreated soil and soil stabilized separately with different amounts (0-10\%) of quick and hydrated limes. The soil mixtures used for the test were compacted at OMC using the BSL compactive effort. While the specimens were in the compaction moulds, they were placed in resealable plastic bags and cured for 28 days in the same conditions as in specimens for UC test. Immediately after the curing, soil specimens were saturated under free-swell conditions by immersing them in water bath. Once swelling reached equilibrium, the saturated soil specimens were subjected to hydraulic conductivity measurements using the

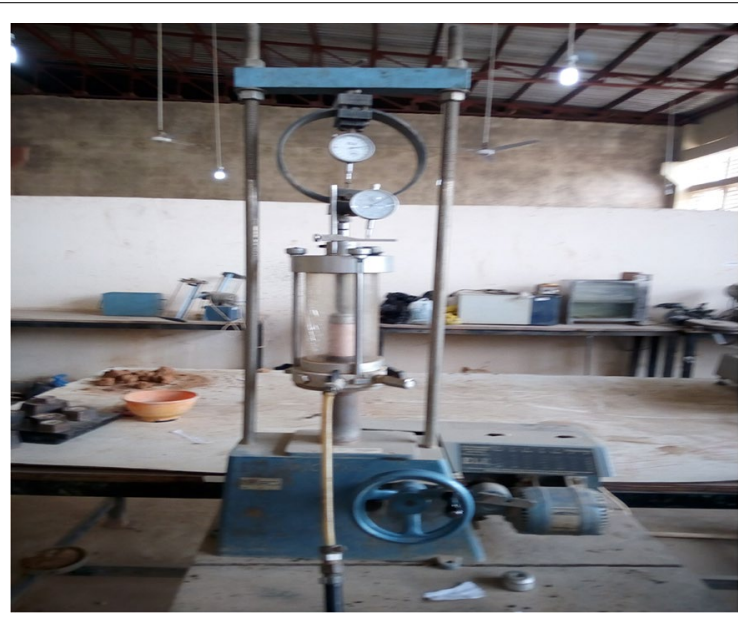

Fig. 3 Triaxial testing setup for unconfined compression test 


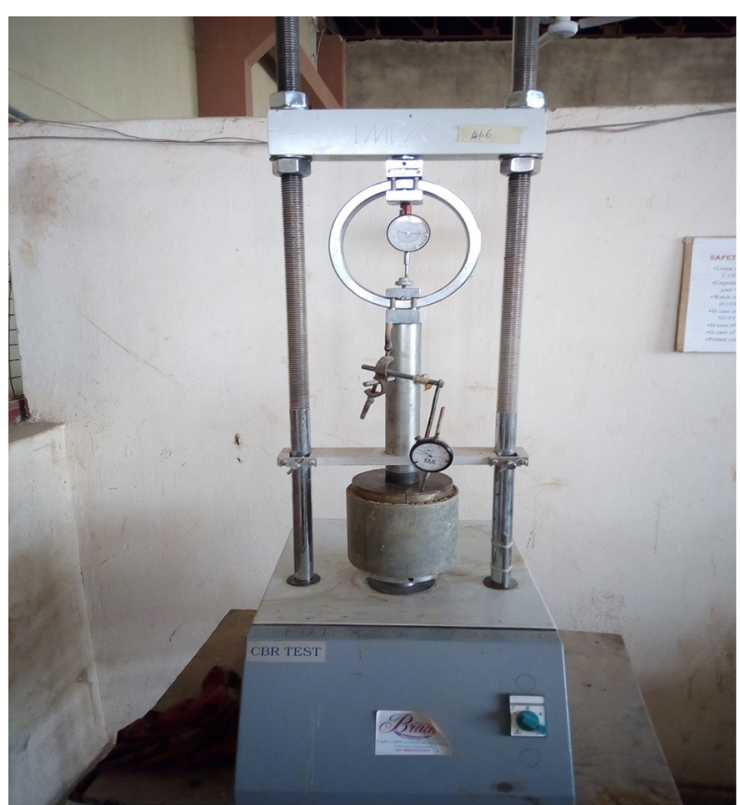

Fig. 4 Laboratory setup for conducting CBR test

falling-head hydraulic system (Fig. 5) following BS 1377 and 1924 [4, 5]. The measurement was continued until the stabilisation of hydraulic conductivity.

\section{Results and discussion}

\section{Engineering classification of natural lateritic soil}

The key characteristics of the untreated (natural) lateritic soil selected for testing, including Unified Soil Classification System (USCS) and AASHTO classifications, grain size analysis, and plasticity data, are summarized in Table 1 , while the oxide composition of the lateritic soil used in the study is reported in Table 2.

The soil classifies as a A-7-6 according to AASHTO soil classification system and a CL or lean clay according to USCS soil classification system. The particle size distribution shows that the soil sample contains about $18 \%$ sand while the silt and clay content constitute about $80 \%$.

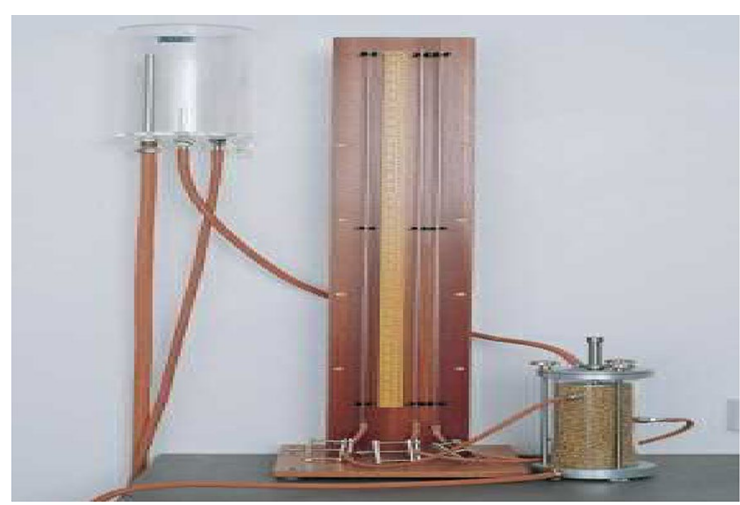

Fig. 5 Laboratory setup of falling head permeameter testing 
Table 1 Classification properties of untreated lateritic soil

\begin{tabular}{ll}
\hline Property & Description/value \\
\hline Natural moisture content (\%) & 20.0 \\
Percent passing No. 4 sieve $(4.75 \mathrm{~mm})$ & 98.4 \\
Percent passing No. 10 sieve $(2.00 \mathrm{~mm})$ & 95.1 \\
Percent passing No. 200 sieve $(0.075 \mathrm{~mm})$ & 80.0 \\
Liquid limit (\%) & 53.0 \\
Plastic limit (\%) & 26.0 \\
Plasticity index (\%) & 27.0 \\
Linear shrinkage (\%) & 18.8 \\
Specific gravity & 2.7 \\
USCS classification & $\mathrm{CH}$ \\
AASHTO classification & $\mathrm{A}-7-6$ \\
Colour & Reddish brown \\
Dominant clay mineral & Kaolinite \\
\hline
\end{tabular}

Table 2 Oxide composition of studied lateritic soil

\begin{tabular}{ll}
\hline Oxide & $\%$ \\
\hline $\mathrm{CaO}$ & 0.26 \\
$\mathrm{SiO}_{2}$ & 34.81 \\
$\mathrm{Al}_{2} \mathrm{O}_{3}$ & 7.77 \\
$\mathrm{Fe}_{2} \mathrm{O}_{3}$ & 14.56 \\
$\mathrm{MgO}$ & 2.4 \\
$\mathrm{SO}_{3}$ & 0.56 \\
$\mathrm{Mn}_{2} \mathrm{O}_{3}$ & 0.89 \\
$\mathrm{~K}_{2} \mathrm{O}$ & $\mathrm{ND}$ \\
$\mathrm{TiO}_{2}$ & $\mathrm{ND}$ \\
$\mathrm{Na}_{2} \mathrm{O}$ & $\mathrm{ND}$ \\
\hline $\mathrm{ND}$ not determined &
\end{tabular}

ND not determined

\section{Plasticity of soil mixtures}

Figure 6 provides information on Atterberg limits of the studied soil treated with the two types of lime and each showed distinct response in modifying the soil. The addition of lime characteristically led to a reduction of liquid limit for both quicklime and hydrated lime specimens. However, more liquid limit reduction occurred in quicklime treated soil rather than soil sample treated with hydrated lime. The liquid limit of specimens reduced from $53 \%$ for the natural soil to 40.8 and $46.28 \%$ respectively when $10 \%$ quicklime and hydrated lime was used.

In contrast, the test results show that the plastic limit increased though slightly on addition of the two types of lime. In this case, similar values at the various percentages of the two types of lime were obtained.

The overall effect of treatment with lime on plasticity characteristics is a reduction of plasticity index (PI) of soil mixtures. Like the liquid limit, the data in Fig. 6 clearly indicates that the modification effect of quicklime was marginally superior to the effect of an equivalent quantity of hydrated lime. While the plasticity index of the soil dropped below $11 \%$ i.e., $10.55 \%$ on addition of $10 \%$ quicklime, specimens treated with the same amount of hydrated lime yielded PI value of $15.28 \%$. 


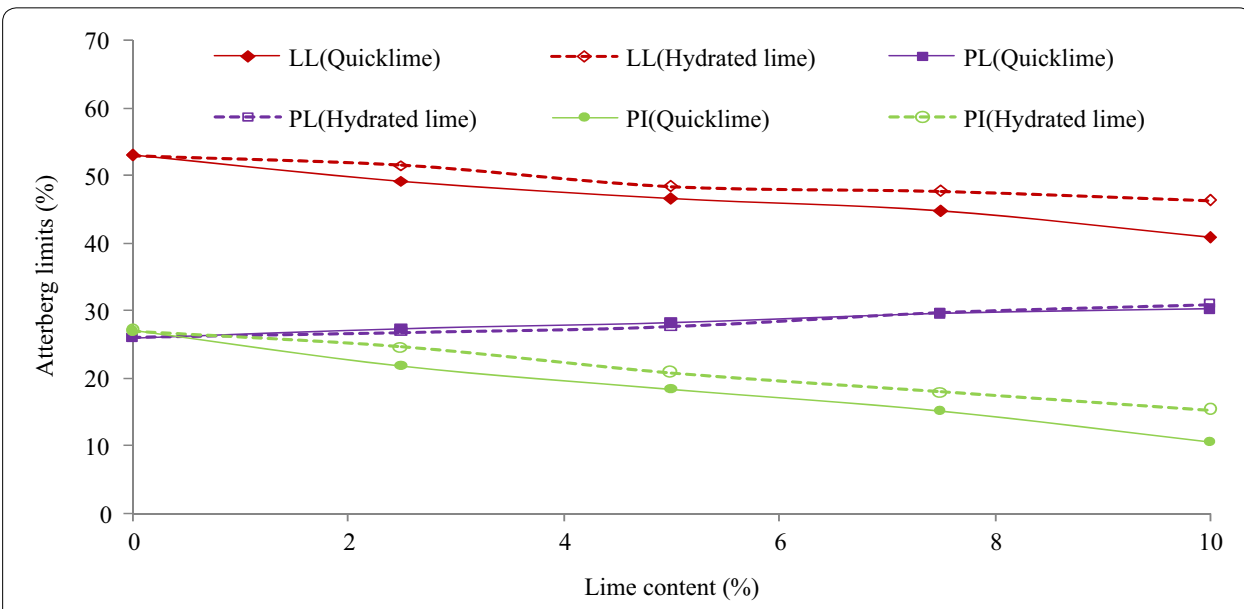

Fig. 6 Variation in Atterberg limits with lime content for the soil stabilized with quicklime and hydrated lime

On the whole, increased lime content resulted in increased plasticity reduction. Similar results have been reported by Dash and Hussain [10], Okoro et al. [21] and Cherian and Arnepalli [6]. As a result, there can be an immediate change in the workability of the material caused in the first instance by cation exchange which occurs when calcium ions released by the lime, exchange with metal ions within or on the clay structure. This cation exchange can increase the plastic limit (PL) and in turn reduce the PI $[18,26]$. With time, as the pozzolanic reactions begin to take effect, the plasticity changes further take place so that the plasticity index continues to decrease. This reduction in plasticity gives the soil-lime mixtures a more friable texture making the soil more amenable to movement and manipulation with field equipment.

\section{Maximum dry unit weight and optimum moisture content of mixtures}

The results of compaction test showed that the maximum dry unit weight $\left(\gamma_{\mathrm{dmax}}\right)$ and the optimum moisture content of the natural soil were $17.4 \mathrm{kN} / \mathrm{m}^{3}$ and $13.6 \%$ respectively. In general, the addition of either quick or hydrated lime resulted in a decrease in the maximum dry unit weight and a slight increase in the optimum moisture content as shown in Figs. 7 and 8. Apparently, hydrated lime treated specimens exhibited higher dry unit weight than that achieved with quick lime addition. The maximum dry unit weight decreased from $17.4 \mathrm{kN} / \mathrm{m}^{3}$ for the natural soil to 12 and $12.88 \mathrm{kN} / \mathrm{m}^{3}$ respectively for specimens treated with quicklime and hydrated lime at $10 \%$ dosage level.

The optimum moisture content of the soil increased from $13.6 \%$ for the untreated soil to 18.14 when $10 \%$ quicklime was used but increased to $17.55 \%$ when the hydrated lime was used. These results indicated that reactions of the quicklime and the soil were very similar to the reactions of hydrated lime.

The reduction in maximum dry unit weight is probably due to the immediate reactions between lime and soil, which is represented by flocculation and agglomeration. In addition, the higher $\mathrm{pH}$ environment in the treated soil changed the surface charge distribution in the clay soil particles, resulting in an increase in repulsion between particle layers. This, along with changes in the particle size distribution, caused a decrease in maximum dry unit weight $[21,23]$. The increases in OMC with increasing lime content may be due to increase of fine fraction and the hydration of lime [10, 15]. 


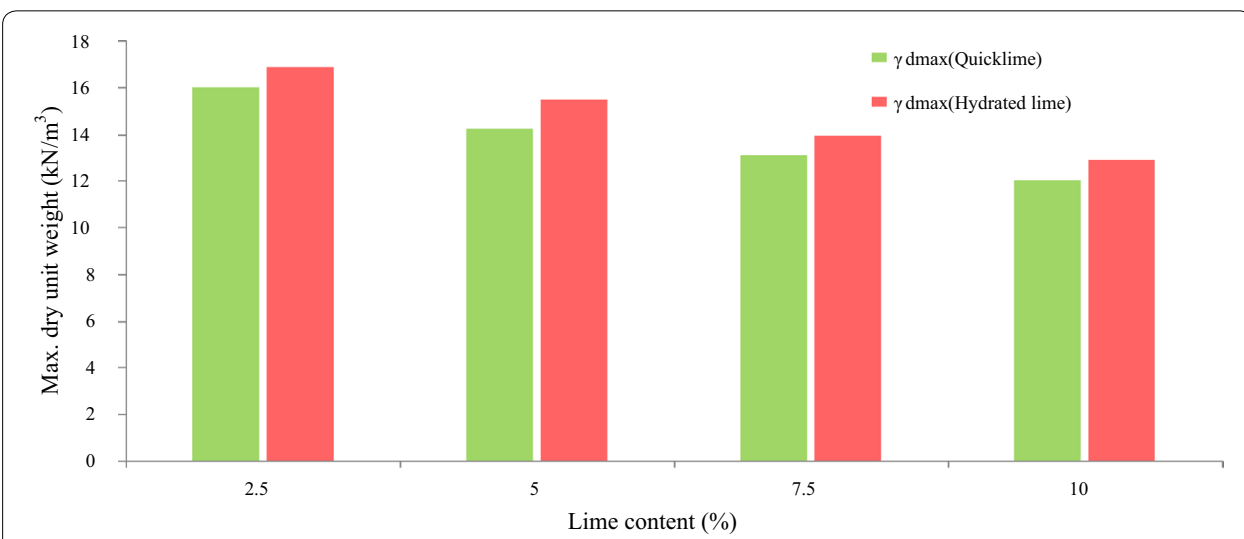

Fig. 7 Changes in maximum dry unit weight with lime content for soil stabilized with quicklime and hydrated lime

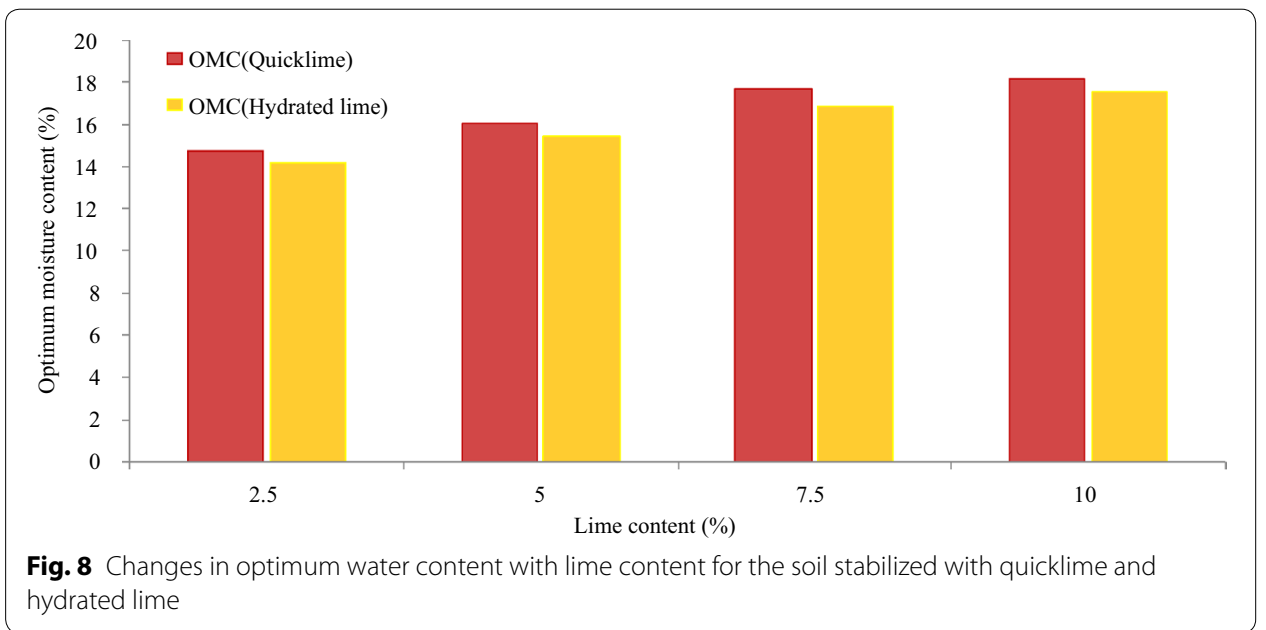

Unconfined compressive strength (UCS)

The variation of UCS with lime content for the natural soil as well as soil stabilized separately with quick and hydrated lime and compacted at OMC using British standard light compactive effort are shown in Fig. 9 and expressed by Eqs. (1) and (2):

$$
\begin{aligned}
& \mathrm{UCS}=78.68 \mathrm{LC}+153.2 \quad \mathrm{R}^{2}=0.996 \\
& \mathrm{UCS}=-3.77(\mathrm{LC})^{2}+85.95 \mathrm{LC}+148.4 \quad \mathrm{R}^{2}=0.984
\end{aligned}
$$

where UCS $=$ unconfined compressive strength $\left(\mathrm{kN} / \mathrm{m}^{2}\right), \mathrm{LC}=$ Lime content (\%).

There is generally an increase in strength with lime content regardless of the type. This is consistent with the results of some past researchers [9, 15, 20, 22, 26]. At low dosage levels $(2.5-5 \%)$ of the two types of lime, quicklime produced only marginally better strength. Also, it can be observed that an approximately linear relation may be considered to exist between UCS and lime content between 0 and 2.5\% lime content.

However, at higher dosage levels (7.5 and $10 \%)$, the trend changed drastically especially for specimens treated with hydrated lime. Quicklime-stabilized soil exhibited higher UCS values than those stabilized with hydrated lime and thus produced a much 


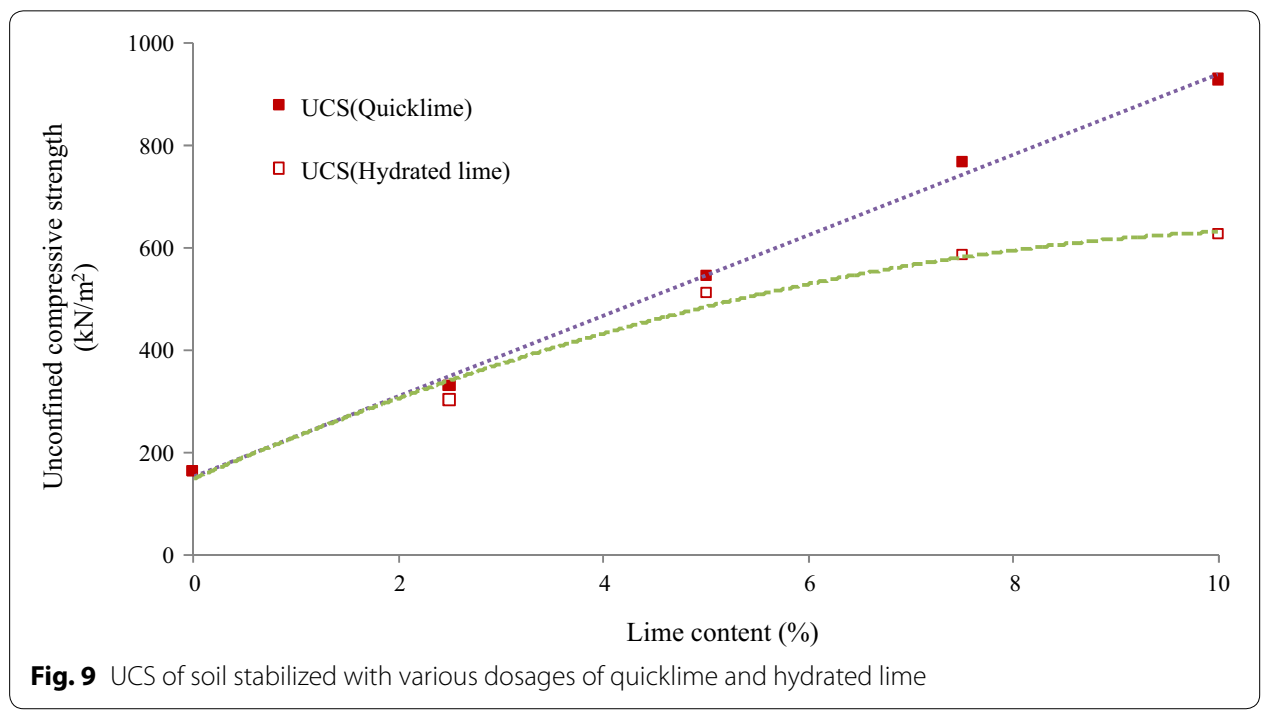

stronger stabilized product. The UCS of the specimens increased from $163 \mathrm{kN} / \mathrm{m}^{2}$ for untreated specimen to $928 \mathrm{kN} / \mathrm{m}^{2}$ for specimens mixed with $10 \%$ of the quicklime which is about six times greater than the strength of the untreated sample. Similar improvement in UCS of lateritic soil stabilized with quicklime was reported by Ola [22], Osinubi and Nwaiwu [23]. Similarly, when 10\% of hydrated lime was used, the UCS was $625 \mathrm{kN} /$ $\mathrm{m}^{2}$, representing approximately a fourfold increase over untreated soil sample. Remarkably, the UCS value of the quicklime mixture at $10 \%$ was only about 1.5 times that of corresponding hydrated lime mixture.

The increase in shear strength of the stabilized soil may be attributed to the physicochemical phenomena namely the cation exchange that takes place between the lime and the negatively charged clay particles together with the flocculation-agglomeration mechanism. These take place rapidly and produce immediate improvements in soil properties including uncured strength and load-deformation properties. In addition, pozzolanic reactions occur later between the calcium ions and the silica and alumina of the clay minerals. This results in the formation of cementitious products such as calcium-silicate-hydrates $(\mathrm{C}-\mathrm{S}-\mathrm{H})$, calcium-aluminate-hydrates $(\mathrm{C}-\mathrm{A}-\mathrm{H})$ and calcium-aluminum-silicate-hydrates (C-A-S$\mathrm{H})$ that are also responsible for the strength increase $[1,7,13,18,27]$.

\section{California bearing ratio (CBR)}

Results of CBR test for the stabilized soil specimens show that the addition of either the quicklime or hydrated lime significantly improved the bearing strength (CBR) of the soil, as shown in Fig. 10. This result is in good agreement with those reported by Chou [7], Du et al. [15] and Zhao et al. [27]. Apparently, quicklime-stabilized specimens proved to be mechanically stronger which indicate a potential to sustain higher bearing loads than hydrated lime-stabilized specimen albeit in small measures at the various dosage levels.

For reference, the CBR value of the natural soil was 8 and $2 \%$ for unsoaked and soaked conditions respectively. When $10 \%$ quicklime was added to the soil, the unsoaked CBR values increased to $76 \%$. On the other hand, soil stabilized with equivalent amount of hydrated lime has unsoaked CBR values of $65 \%$. 


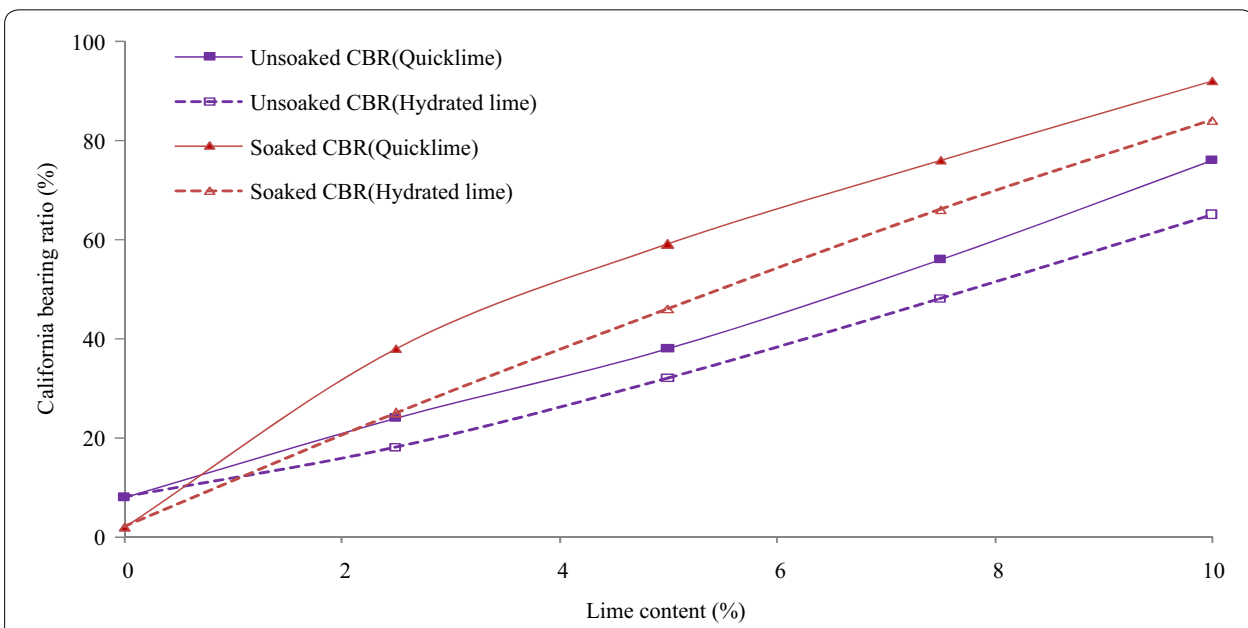

Fig. 10 Variation of standard CBR values (unsoaked and soaked) for the various percentages of quicklime and hydrated lime

Remarkably, the soaked CBR values are even higher than the unsoaked values for both quicklime and hydrated lime-stabilized soil. The soaked quicklime-stabilized specimens however showed significantly higher CBR values than the hydrated lime-stabilized soil at all dosages.

The increase in the soaked CBR is expected because of gradual formation of cementitious compounds namely calcium-silicate-hydrates $(\mathrm{C}-\mathrm{S}-\mathrm{H})$, calcium-aluminatehydrates $(\mathrm{C}-\mathrm{A}-\mathrm{H})$ and calcium-aluminum-silicate-hydrates $(\mathrm{C}-\mathrm{A}-\mathrm{S}-\mathrm{H})$ associated with renewed hydration of the lime and the pozzolanic reactions [15, 27].

In terms of durability of stabilized soil determined by prolonged exposure to moisture, values of CBR of specimens soaked for 28-days are shown in Fig. 11. The longer soaking period significantly affected the CBR values. The CBR values for extended soaking period increased by 108 and $96 \%$ on addition of $10 \%$ quick and hydrated lime respectively over the untreated soil. Here again, the performance of quicklime was only slightly better at higher dosage levels (7.5-10\%). The CBR value of the quicklime mixture recorded at $10 \%$ is approximately $12.5 \%$ higher than that of the corresponding hydrated lime mixture. Similarly, CBR values for extended soaking period is about 1.2 times when compared to that of the standard CBR test at $10 \%$ quick lime although less for hydrated lime treated specimens. These results indicate that when the soil-lime mixtures are in the presence of water, increased cementation reactions between the lime and soil that results in continuous formation of cementitious products such as calcium aluminate hydrates (CAH) and calcium silicate hydrates $(\mathrm{CSH})$ that leads to gradual increase in strength occur $[9,12,15]$.

\section{Swell potential}

Results of the CBR swell test provided in Fig. 12 highlights the performance as well as the efficiency of the two types of lime in reducing the swelling potential of the soil. It is obvious that the two types of lime are effective in reducing swelling potential.

The swell values reached by specimens treated with quicklime are marginally lower than that of hydrated lime. For the untreated specimen, the swell value stabilized at $8.75 \%$. However, for the quicklime-treated specimens, the maximum swell value 


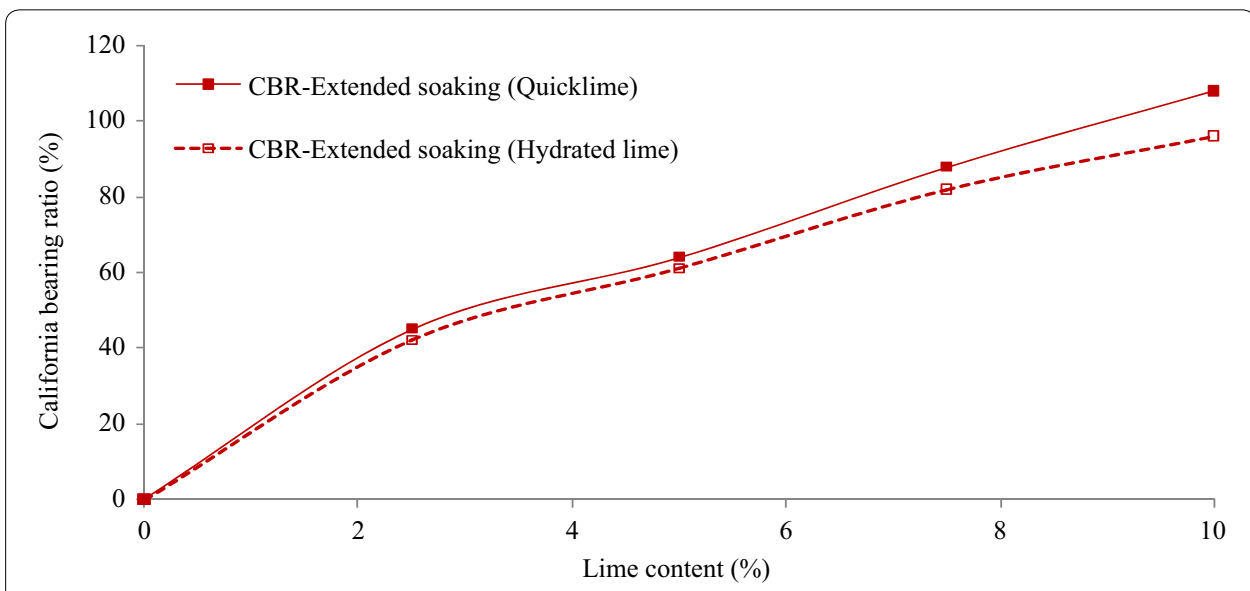

Fig. 11 Variation of CBR values (extended soaking period) for the various percentages of quicklime and hydrated lime

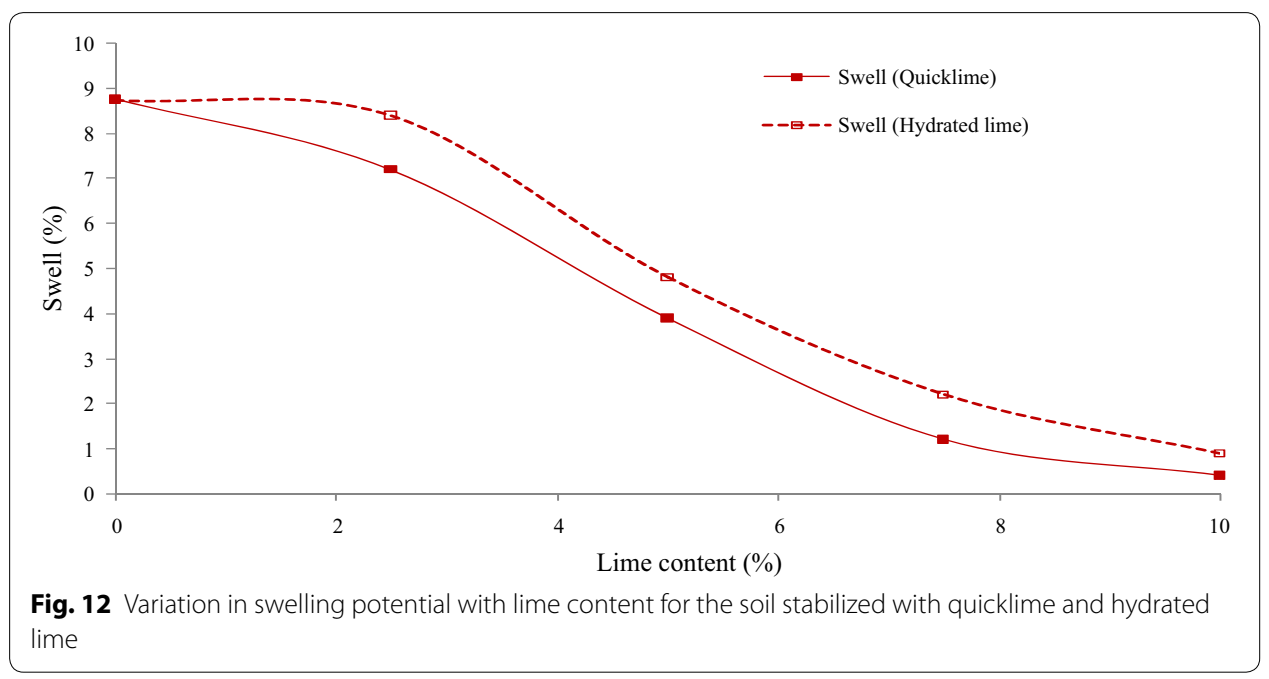

observed in the presence of $10 \%$ lime content is $0.40 \%$. For the equivalent amount of hydrated lime, the swell percent was $0.89 \%$.

When lime is added to the soil, it causes (a) cation exchange and (b) flocculationagglomeration of clay particles. The combination of these two phenomena allows the small clay particles to floc together resulting in agglomerate of larger clay particles [18]. The net result is a substantial decrease in swelling characteristics of the soils. In addition, the pozzolanic reactions between lime and soil, which usually occurs after sufficiently long time, forms a cementitious matrix resulting in the resistance to volumetric expansion of soil to an appreciable extent.

Overall, when lime is added to soil, reduction in swell potential occurs primarily because of alteration in clay structure $[18,25,26]$.

\section{Hydraulic conductivity}

Figure 13 shows the hydraulic conductivity values of the quick and hydrated lime stabilized lateritic soil. The trend of the hydraulic conductivity for quicklime mixtures is 


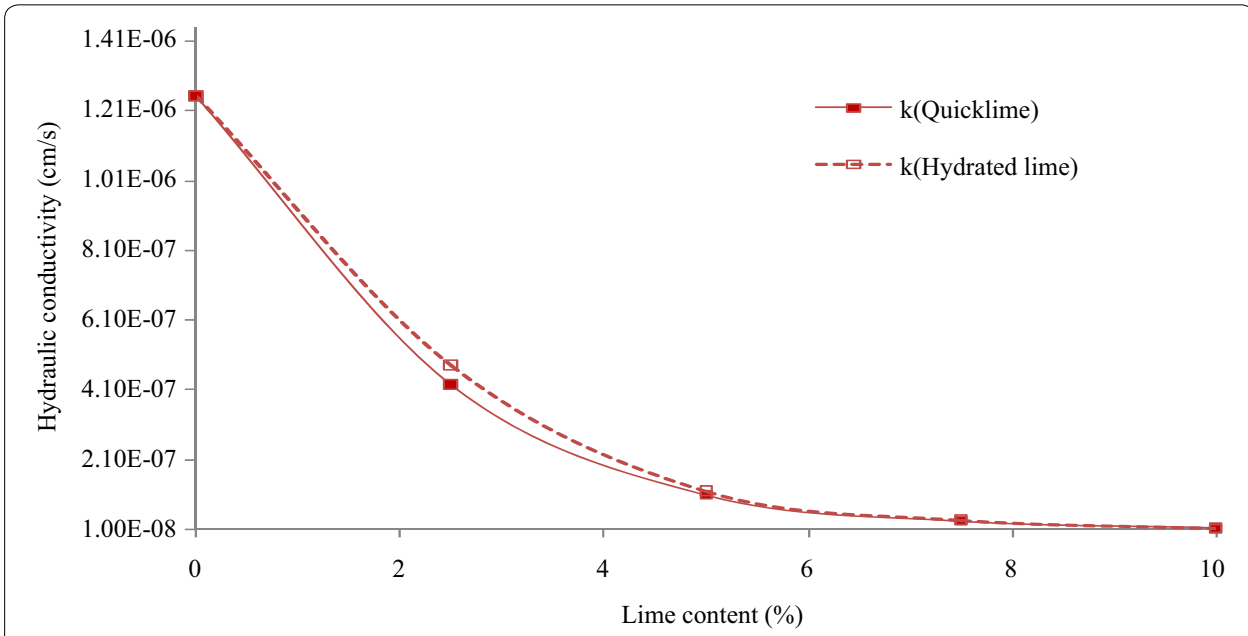

Fig. 13 Variation in hydraulic conductivity with lime content for the soil stabilized with quicklime and hydrated lime

similar and of the same order of magnitude to that of hydrated lime mixtures. The closeness in hydraulic conductivity values for both types of lime at various dosages suggests that the tortuosity or the pore connectivity developed in the stabilized system is similar $[11,14,20]$.

It can also be observed that the hydraulic conductivity of the specimens treated with $10 \%$ lime (quick or hydrated) is about two orders of magnitude higher than that of the untreated specimens.

The decrease in hydraulic conductivity of treated soils is explained by the development of the cementitious materials due to the pozzolanic reaction that filled the pores $[14,20]$.

It is important to note that the decreasing trend in the relationship between hydraulic conductivity and lime content is similar to the trend exhibited by the swelling potential. As with the results of the swell test, the changes in hydraulic conductivities are consistent with changes in the thickness of the adsorbed layer $[11,18]$.

\section{Conclusions}

This investigation was performed to evaluate the performance of quicklime and hydrated lime in stabilizing and improving engineering properties of lateritic soil. In order to make a one-to-one comparison between the performances of quick and hydrated lime as stabilizer, the dosages and testing methods were kept the same. Several characteristics, including engineering properties and long-term durability, were investigated. The following general conclusions can be drawn based on the investigation performed.

Quicklime caused the soil to have plasticity 1.4 times lower than that produced by hydrated lime at $10 \%$ treatment, yielded higher strengths (approximately $50 \%$ higher than value achieved by hydrated lime at $10 \%$ treatment) and resulted in swell values about 2.2 times lower than the value observed for hydrated lime at $10 \%$ treatment. Marginal superiority of quick lime was recorded in terms of durability of mixtures (108 and $96 \%$ respectively for quick and hydrated lime at $10 \%$ treatment over the untreated soil), while soil-hydrated lime mixtures yielded somewhat higher dry unit weights (12.88\% for 
hydrated lime against $12 \mathrm{kN} / \mathrm{m}^{3}$ for quick lime). Meanwhile, no appreciable distinction in hydraulic conductivity was observed. In general, the performance of quicklime stabilized soil proved superior to hydrated lime in most the characterizations performed.

\begin{abstract}
Authors' contribution
AAA developed the concept, designed the experiments and prepared the manuscript. AO performed the experiments. Both authors read and approved the final manuscript.
\end{abstract}

\title{
Competing interests
}

The authors declare that there is no competing interests.

Received: 9 September 2016 Accepted: 13 February 2017

Published online: 01 March 2017

\section{References}

1. Alzubaidi R, Lafta S (2013) Effect of strain rate on the strength characteristics of soil-lime mixture. Geotech Geol Eng. doi:10.1007/s10706-013-9653-3

2. Beckham TL, Hopkins TC (1997) Stabilization of subgrade soil using hydrated lime product. University of Kentucky, Kentucky Transportation Center, Lexington. Report No. KTC-97-19

3. Bell FG (1996) Lime stabilization of clay minerals and soils. Eng Geol 42(4):223-337. doi:10.1016/0013-7952(96)00028-2

4. BS 1377 (1990) Methods of tests for soils for civil engineering purposes. British Standards Institute, London

5. BS 1924 (1990) Methods of testing for stabilized soils. British Standards Institute, London

6. Cherian C, Arnepalli D (2015) A critical appraisal of the role of clay mineralogy in lime stabilization. Int J Geosynth Ground Eng. doi:10.1007/s40891-015-0009-3

7. Chou L (1987) Lime stabilization: reaction, properties, design and construction, State of the Art Report 5, Transportation Research Board, Washington, DC

8. Clare KE, Cruchley AE (1957) Laboratory experiments on the stabilization of clays with hydrated lime. Geotechnique 7:97-100

9. Consoli N, Prietto P, da Silva Lopes L, Winter D (2014) Control factors for the long term compressive strength of lime treated sandy clay soil. Transp Geotech. doi:10.1016/j.trgeo.2014.07.005

10. Dash S, Hussain M (2012) Lime stabilization of soils: reappraisal. J Mater Civ Eng. doi:10.1061/(ASCE) MT.1943-5533.0000431

11. de Brito Galvão T, Elsharief A, Simões G (2004) Effects of lime on permeability and compressibility of two tropical residual soils. J Environ Eng 130(881):881-885. doi:10.1061/(ASCE)0733-9372

12. Dempsey BJ, Thompson MR (1968) Durability properties of lime-soil mixtures. Highway Research Record No. 235. National Research Council, Washington DC, pp 61-75

13. Diamond S, Kinter EB (1965) Mechanisms of soil-lime stabilization. Highway Res Rec 92:83-102

14. Di Sante M, Fratalocchi E, Mazzieri F, Brianzoni V (2015) Influence of delayed compaction on the compressibility and hydraulic conductivity of soil-lime mixtures. Eng Geol. doi:10.1016/j.enggeo.2014.12.005

15. Du Y, Zhang Y, Liu S (2012) Investigation of strength and California bearing ratio properties of natural soils treated by calcium carbide residue. Geo Front 2011:1237-1244

16. Frempong EM (1995) A comparative assessment of sand and lime stabilization of residual micaceous compressible soils for road construction. Geotech Geol Eng 13:181-198

17. Jayanthi P, Singh D (2016) Utilization of sustainable materials for soil stabilization: State-of-the-Art. Adv Civ Eng Mater. doi:10.1520/ACEM20150013

18. Jha A, Sivapullaiah P (2015) Mechanism of improvement in the strength and volume change behavior of lime stabilized soil. Eng Geol. doi:10.1016/j.enggeo.2015.08.020

19. Latifi N, Marto A, Eisazadeh A (2016) Physicochemical behavior of tropical laterite soil stabilized with non-traditional additive. Acta Geotech. doi:10.1007/s11440-015-0370-3

20. Locat J, Trembley H, Leroueil S (1996) Mechanical and hydraulic behaviour of a soft inorganic clay treated with lime. Can Geotech J 33(4):654-669

21. Okoro C, Vogtman J, Yousif A, Agnaou M, Khoury N (2012) Consolidation characteristics of soils stabilized with lime, coal combustion product, and plastic waste. Geo Front 2011:1202-1209

22. Ola SA (1977) The potentials of lime stabilization of lateritic soils. Eng Geol 11:305-317

23. Osinubi KJ, Nwaiwu MO (2006) Compaction delay effects on properties of lime-treated soil. J Mater Civ Eng 18(2):250-258

24. Thompson MR (1966) Lime reactivity of illinois soils. J Soil Mech Found Div ASCE 92(SM5):67-92

25. Thyagaraj T, Rao S, Sai Suresh P, Salini U (2012) Laboratory studies on stabilization of an expansive soil by lime precipitation technique. J Mater Civ Eng. doi:10.1061/(ASCE)MT.1943-5533.0000483

26. Thyagaraj T, Zodinsanga S (2014) Laboratory investigations of in situ stabilization of an expansive soil by lime precipitation technique. J Mater Civ Eng. doi:10.1061/(ASCE)MT.1943-5533.0001184

27. Zhao H, Liu J, Guo J, Zhao C, Gong B (2014) Reexamination of lime stabilization mechanisms of expansive clay. J Mater Civ Eng. doi:10.1061/(ASCE)MT.1943-5533.0001040 